\title{
Tecnología de género y ley penal en América Latina y El Caribe
}

\author{
Gender technology and criminal law in Latin America and the \\ Caribbean
}

\author{
Tecnologia de gênero e legislação penal na América Latina e \\ no Caribe
}

\section{Alina Herrera Fuentes*}

\section{RESUMEN}

El concepto de tecnologías de género fue desarrollado por la teórica feminista Teresa de Lauretis para explicar los procesos de construcción del género mediante tecnologías sociales, narrativas y representaciones. Este estudio se propone hacer un análisis extensivo del concepto respecto de las leyes penales y la tipificación de delitos como el feminicidio, el transfeminicidio, el travesticidio, el afrofemicidio y el femigenocidio, incluyendo sus limitaciones y contradicciones que conforman, a su vez, procesos de construcción del género en diferentes dimensiones y alcances. La investigación se enmarca en algunos países de América Latina y el Caribe como México, Argentina, Cuba, Colombia, Honduras, Guatemala y el Salvador.

\section{ABSTRACT}

Feminist theorist Teresa de Lauretis developed the concept of gender technologies to explain the processes of gender construction through social technologies, narratives, and representations. This study proposes an extensive analysis of criminal laws and the classification of crimes such as femicide, transfeminicide, transvesticide, afrofemicide, and femigenocide, including their limitations and contradictions that shape processes of gen-
Palabras clave: ley penal, feminicidio, femigenocidio, tecnología de género, transfeminicidio/ travesticidio.

Keywords: criminal law, feminicide, femicide, femigenocide, gender technology, transfeminicide/ travesticide.

* Cubana. Licenciada en Derecho por la Universidad de La Habana; Maestrante en Género, Políticas y Sociedad en FLACSO Argentina. Instituto Nacional de Formación Política - Seminario Interinstitucional de Feminismos. Ciudad de México, México. alinaherrerafuentes@gmail.com 
der construction in different dimensions and scopes. We base our research on Latin American and Caribbean countries such as Mexico, Argentina, Cuba, Colombia, Honduras, Guatemala, and El Salvador.

\section{RESUMO}

O conceito de tecnologias de gênero foi desenvolvido pela teóPalavras-chave: rica feminista Teresa de Lauretis para explicar os processos de construção do gênero mediante tecnologias sociais, narrativas e representações. Este estudo se propõe a fazer uma análise aprofundada do conceito com relação às leis penais e à tipificação de crimes como feminicídio, transfeminicídio, travesticídio, feminicídio de mulheres negras e femigenocídio, incluindo suas limitações e contradições que conformam, por sua vez, processos direito penal, femicídio, femigenocídio, tecnologia de gênero, transfemicídio / transvesticida. de construção do gênero em diferentes dimensões e alcances. A pesquisa abrange alguns países da América Latina e do Caribe como México, Argentina, Cuba, Colômbia, Honduras, Guatemala e El Salvador. 


\section{Introducción}

El estudio de las leyes penales y de la tipificación de delitos como el feminicidio, el transfeminicidio y el travesticidio, hacen pensar en que no solo estamos ante la presencia de nuevos tipos penales en un marco teórico adscripto a la corriente positivista y legalista, sino que también nos encontramos frente a tecnologías de género partiendo del desarrollo conceptual que nos ha planteado Teresa de Lauretis (1989) en su obra homónima.

Estas tipificaciones han encontrado voces detractoras desde corrientes feministas que abogan por la abolición del género hasta penalistas que cuestionan la pertinencia de esta "inflación penal", sobre todo porque plantean que la igualdad efectiva entre las personas de diversos géneros no se alcanza mediante la aplicación del derecho penal y mucho menos mediante la creación de nuevos tipos penales.

También existen vertientes feministas que se posicionan en contra del punitivismo carcelario que muchas veces acompaña al proceso de creación de nuevas figuras delictivas a través del agravamiento de las penas y que, en efecto, consideran que la dureza retributiva y el aumento de años en las cárceles no favorece la articulación de un mundo alternativo que soñamos donde prime la justicia social. Aunque el presente trabajo no se enfoca en el tema punitivo, había que señalar la pertinencia de esta discusión necesaria y útil.

En aras de desenredar estos nudos críticos y de alcanzar mayor claridad teórica y metodológica durante el desarrollo del presente estudio, es importante partir de las siguientes preguntas investigativas: ¿cómo afecta la ley penal a las mujeres y personas con otras identidades de género víctimas de la violencia en los distintos territorios de América Latina y del Caribe según una perspectiva de género e interseccional? ¿Cómo se inserta ese análisis en la discusión acerca de la pertinencia de tipos penales como el feminicidio, transfeminicidio, travesticidio, afrofeminicidio y femigenocidio como expresiones finales de un contínuum de violencias de género?

Como objetivos, el texto pretende establecer la necesidad de un debate jurídico-penal que integre la perspectiva de género e interseccional en las leyes penales en tanto estas son consideradas tecnologías de género, a partir de un estudio comparativo, tanto a través 
del derecho comparado como por medio del análisis de estadísticas respecto de tasas de feminicidio, tasas de homicidio, encuestas de percepción de la violencia de género, cifras de la composición racial y de género y algunos estudios de casos, de distintos países de la región. Asimismo, se pretende con esta investigación demostrar las peculiaridades de la violencia basada en género presente en estos territorios, debido a las lógicas de un sistema capitalista mundial en donde nuestros países ocupan un lugar geopolítico específico para el extractivismo y la producción de capitales trasnacionales y en donde, en la misma medida, son situados los cuerpos de las mujeres y personas género-disidentes.

Como hipótesis, la propuesta plantea la ley penal como una tecnología de género en tanto las mujeres y otras subjetividades subalternizadas por motivos de género y por otros vectores de opresión como la raza, el territorio y la clase, no se encuentran reconocidas de manera integral y transversal en las normas penales y, por ende, continúan confinadas a la periferia del sistema de justicia penal como cuerpos no "justiciables", sino como cuerpos descartables en sintonía con el sistema capitalista y patriarcal que nos subsume. La ley penal sigue dirimiendo algunos asuntos que aparentemente son "domésticos" sin adecuarse axiológica y dialécticamente a la altísima conflictividad social y a las desigualdades de género, raciales y territoriales de nuestra región.

Además, la exclusión (e incluso la expulsión) de la diversificación de géneros en las leyes penales forma parte también del reforzamiento de la dominación heterocispatriarcal, racista y colonial, es decir, que sin la asimilación de nuevos tipos penales que perforen el monolito misógino y transexcluyente de la ley penal, no solo no alcanzaremos la igualdad, sino que estaremos más lejos de lograrla.

El análisis histórico y situado es otro de los elementos vertebradores del presente texto. Es imprescindible comprender el lugar espacial, temporal y territorial donde nos encontramos como movimientos de mujeres y de comunidades LGBTIQ+. En la misma tesitura, se hace necesario articular la dogmática penal con los fines también culturales y educativos del derecho. El sueño positivista reduce la aplicación de la ley penal a un caso concreto y sus fines mueren allí, en esa relación víctima-victimario, sin embargo, sabemos que las desigualdades y las 
violencias basadas en género son estructurales, históricas y colectivas, que las relaciones interpersonales son extensiones de un sistema de capitalismo global donde los países de América Latina y el Caribe cumplen un rol fundamental para la acumulación de capitales financieros trasnacionales; y los métodos para cumplir con ese rol son en su mayoría el extractivismo, la explotación, la cosificación de la vida y el crimen organizado, y en ello el cuerpo de las mujeres es uno de los territorios donde se disputan los poderíos empresariales.

Entonces, para nuestro caso, apelo a que las leyes penales sean más que norma, que se conviertan también en tecnologías de género resquebrajadoras de la dominación masculina, colonial y capitalista.

\section{Tecnología de género y leyes penales}

Resulta cada vez más frecuente, en el campo del Derecho y las leyes, hacer referencia a la necesaria "perspectiva de género". Incluso, en la praxis y cultura jurídica, también coincide una tendencia del uso de la "perspectiva de género" sin una mayor problematización acerca de las epistemologías feministas que le han dado lugar y relevancia.

La carga valorativa e interpretativa de la perspectiva de género en estos usos pareciera ser sinónimo de un sujeto mujer, homogéneo y universal, cisgénero, heterosexual, blanco y de clase media, en contraposición con el hombre de similares condiciones. Como dijera Paula Viturro (2006), "se trata de una expresión resbaladiza, que suele funcionar en el ámbito del discurso jurídico como un truismo que oculta más de lo que muestra, y que da lugar a complejas y gravosas consecuencias políticas para quienes pretende favorecer" (p. 295).

La jerarquización, la discriminación y las violencias que sufren los cuerpos no atribuidos al concepto universalista y uniforme de mujer/ hombre en su lógica binaria y biológica descritos con anterioridad, quedan por fuera de este núcleo de relaciones sociales y jurídicas.

No es que sea aditiva la subalternidad en el plano legal, sino que se trata más bien de perforar los blindajes de una tradición teórica y de una práctica masculinista, biologicista y binaria. Si bien los dilemas de las construcciones identitarias, las representaciones y los esencialismos implican por un lado el reforzamiento de patrones producidos por el heteropatriarcado, por el otro producen una contranorma que 
significa la existencia misma de estos sujetos en el orden cotidiano e institucional.

El género, como categoría analítica y discursiva en la crítica feminista, es un término siempre en disputa. Cristina Palomar (2016) se ha referido a la trayectoria de este concepto como un significante vacío, debido a la utilización ambigua por donde ha transcurrido, desde su uso equivalente a la diferencia sexual binaria hasta su debate teórico contemporáneo que somete a revisión los esencialismos identitarios y en el que se inserta su tesis de que el género indica un lugar vacío que puede ser ocupado por cualquier persona, como resultado de una categoría imaginaria que "no tiene como referencia en lo real a un tipo de persona, sino que se trata de una posición simbólica en un conjunto de relaciones formales definidas por el principio ordenador de género" (p. 40)

Gloria Bonder (1998), por su parte, asegura que la crítica feminista, desde su posicionamiento situado e histórico, ha descolocado las narrativas de las zonas de confort epistémicas para aterrizarlas, forzosamente, en la política y en la interacción entre saber y poder. De ahí que la inestabilidad del concepto de género deba entenderse como enriquecedora para los debates y análisis teóricos, pero también para sus usos y articulación. Para Bonder (1998), entonces, el género ha dejado de ser la categoría que explica todas las problemáticas relacionadas con las desigualdades y otras situaciones sociales de las mujeres, "para convertirse en el centro de una controversia que de una u otra manera va construyendo una 'genealogía política de las ontologías del género"' (párrafo 20).

Desde la segunda ola feminista se pueden detectar demandas en común entre el movimiento de mujeres y el de colectivos LGBTIQ+, sobre todo desde la crítica a la sexualidad, a los roles de género y a las relaciones de género, aspectos que se ubican en contraposición a las normas legales, generalmente constituidas por patrones biologicistas.

Maxine Molyneux (2017) ha declarado que si bien las leyes no son el único vehículo para posicionar los derechos de las mujeres y de los colectivos LGBTIQ+, es indiscutible que son instrumentos muy poderosos para la resistencia y la transformación de los derechos y las realidades de estos sujetos. 
En este punto de significancia de las leyes y las normas jurídicas, ¿cómo es posible interpretarlas como tecnologías de género?

Es Teresa de Lauretis (1989) quien incorpora la "tecnología de género" como herramienta analítica que permite, primero, deshebrar la insuficiencia de constreñir el género como equivalencia de la diferencia sexual; segundo, comprender las relaciones de subjetividad en torno al género mediante las representaciones lingüísticas, culturales, raciales, de clase, dadas a través de tecnologías sociales que pueden ser desde las narrativas, las prácticas críticas, las epistemologías hasta los discursos institucionales y la vida diaria.

Para la teórica feminista es así como el género no representa a un individuo sino a una relación, en tanto que la construcción del género es su resultado como también su proceso de representación. Asimismo, la construcción del género se encuentra, además, en las periferias del discurso hegemónico, en las fuerzas que desde los márgenes produce su deconstrucción, desestabilizando las representaciones hegemónicas e institucionales.

Esta práctica crítica, situada por fuera del núcleo cisheteropatriarcal, llamada por la autora como micropolítica, debe ser comprendida también como parte de la construcción del género. Los efectos de este hacer/pugnar distinto y otro, se infiltran en los centros de poder-saber, en las políticas macro, en las instituciones y en las leyes. Entonces, producir representaciones de género y significaciones sociales de lo que son los géneros abarca también la "contraproducción" y la "deconstrucción" hegemónica de las diferencias sexuales binarias, entendidas siempre desde preeminente proyección de lo masculino/varón.

La perforación de las políticas y de las leyes por esta construcción de género diferente no solo despliega efectos en el reconocimiento de las subjetividades y de las autopercepciones/autorrepresentaciones, también inciden en la capacidad de agencia de los movimientos de mujeres y colectivos LGTBIQ+, en los recursos de poder y en las resistencias cotidianas.

Ante esto, las leyes penales no son una excepción. La violencia de género forma parte de las estructuras sobre las que se montan y manifiestan las desigualdades basadas en el género. La violencia de género, 
que puede corporizarse en las leyes penales mediante la tipificación de los delitos y su procesamiento e investigación, hace que la aplicación de estas y su articulación construyan y deconstruyan también al género tal y como lo hemos visto hasta acá, es decir, como tecnología de género.

El género (aunque también la condición racial, de clase, de nacionalidad, etc.) en las leyes penales ha determinado qué es o no delito, ha delineado términos como el consentimiento a favor de la impunidad masculina, ha desbalanceado la carga y la descarga de pruebas, ha establecido qué cuerpos y subjetividades son reconocidos y amparados por la justicia penal y cuáles no lo están.

Las leyes penales también han construido a un sujeto mujer cisuniforme y homogéneo, que se (re)victimiza y desagencia y que debe cumplir con determinados relatos atribuibles a una buena mujer, o sea, una buena víctima; siempre como proyección de la supremacía masculina (en términos binarios) y acotada al cumplimiento estricto de los roles de género. Incluso, la ley penal somete a un rol y a un estereotipo específico de género a las mujeres que acuden a la justicia penal por razones de violencia basada en género: apariencia, vestimenta, conducta, subordinación, ocupación y hasta altos niveles de sufrimiento manifiesto. Por supuesto que la cisgeneridad y la heteronormatividad también moldean a la buena víctima.

La pluralidad de subjetividades que giran en torno al género, queda fuera de la violencia de género y por tanto desprotegidas y desconocidas por la ley penal. No obstante, la disputa por su reconocimiento y regulación cada vez más amplia y pujante le agrega (de)construcciones de género a la justicia penal. Estas grietas producidas en la monolítica concepción binaria también modelan la ley penal como tecnología de género.

Una parte importante de las demandas de los colectivos de mujeres y/o feministas ha sido la especialización del homicidio o del asesinato en las leyes penales, es decir, el reconocimiento del feminicidio o femicidio como un tipo penal específico.

Desde que Diana Russell usara por primera vez el término femicidio (femicide en inglés) en un espacio feminista dedicado exclusivamente para hablar acerca de la violencia contra las mujeres, como lo 
fue el Primer Tribunal Internacional de Crímenes contra Mujeres en Bruselas en el año 1976, el concepto ha sido ampliado y diversificado debido al des-molde que ha sufrido también la categoría "género" como equivalencia a la diferencia sexual.

Inicialmente, serían los cuerpos de las mujeres (cis) y las niñas los que constituían el delito. La misma Russell comenzó a teorizar respecto del término a partir de 1990 y junto a Jill Radford (1992) definieron que el femicidio sería el asesinato misógino de mujeres cometido por hombres.

No obstante, Russell no se limita a conceptualizar este resultado final de la violencia de género, sino que describe el encadenamiento de violencias que puede concluir en el asesinato de las mujeres debido, centralmente, a su condición de mujeres:

El femicidio representa el extremo de un contínuum de terror antifemenino que incluye una amplia variedad de abusos verbales y físicos, tales como: violación, tortura, esclavitud sexual (particularmente por prostitución), abuso sexual infantil incestuoso o extrafamiliar, golpizas físicas y emocionales, acoso sexual (por teléfono, en las calles, en la oficina, y en el aula), mutilación genital (clitoridectomías, escisión, infibulaciones), operaciones ginecológicas innecesarias (histerectomías), heterosexualidad forzada, esterilización forzada, maternidad forzada (por la criminalización de la contracepción y del aborto), psicocirugía, negación de comida para mujeres en algunas culturas, cirugía plástica y otras mutilaciones en nombre del embellecimiento. Siempre que estas formas de terrorismo resultan en muerte, se convierten en femicidios. (Russell, 2001, citada por Maffía, 2018, p. 79)

Ciertamente la teorización y la ley actuarían, en este caso, como un reforzamiento de las identidades binarias, no obstante, la invisibilización por parte de la ley penal en cuanto a las violencias basadas en género y sus especiales causas, sostiene la inexistencia de esas desigualdades estructurales allí donde, supuestamente, se impartiría justicia frente a fenómenos delictivos o criminales.

La igualdad ficcional del hombre y la mujer ante la ley resulta calada cuando las teorías críticas feministas sobre violencia de género irrumpen también en el campo de la teoría y la justicia penal. 


\section{El feminicidio en el caso de México}

La antropóloga feminista Marcela Lagarde (2005) se basa en el concepto de femicidio desarrollado por Russell y Radford para agregarle la connotación de crimen de Estado como consecuencia de la impunidad estructural que caracteriza el sistema de justicia mexicano en general y todo el conjunto de violaciones a los derechos humanos de las mujeres en particular. Ante esto, el feminicidio, para la teórica, es solo la punta del iceberg.

La cosificación del cuerpo de las mujeres y el reforzamiento de estereotipos de género concurren en las representaciones sociales, culturales y lingüísticas, ya no solo como narrativas de género, sino también como violencias de género en el campo de lo simbólico y de lo psicosocial. Estas violencias son masivamente difundidas en los espacios públicos y privados sin que el Estado actúe en correspondencia con el respeto a los derechos humanos de las mujeres (Lagarde, 2005).

Para Lagarde (2005), el feminicidio además de absorber un contínuum de violencias generadas por las desigualdades de género, también acoge un conjunto de tecnologías de género que las reproducen, naturalizan y legitiman.

Luego de una larga trayectoria de propuestas para tipificar el feminicidio como delito federal, en el año 2012 quedó regulado de la siguiente manera:

Comete el delito de feminicidio quien prive de la vida a una mujer por razones de género. Se considera que existen razones de género cuando concurra alguna de las siguientes circunstancias:

I. La víctima presente signos de violencia sexual de cualquier tipo;

II. A la víctima se le hayan infligido lesiones o mutilaciones infamantes o degradantes, previas o posteriores a la privación de la vida o actos de necrofilia;

III. Existan antecedentes o datos de cualquier tipo de violencia en el ámbito familiar, laboral o escolar, del sujeto activo en contra de la víctima;

IV. Haya existido entre el activo y la víctima una relación sentimental, afectiva o de confianza; 
V. Existan datos que establezcan que hubo amenazas relacionadas con el hecho delictuoso, acoso o lesiones del sujeto activo en contra de la víctima;

VI. La víctima haya sido incomunicada, cualquiera que sea el tiempo previo a la privación de la vida;

VII. El cuerpo de la víctima sea expuesto o exhibido en un lugar público.

A quien cometa el delito de feminicidio se le impondrán de cuarenta a sesenta años de prisión y de quinientos a mil días multa.

Además de las sanciones descritas en el presente artículo, el sujeto activo perderá todos los derechos con relación a la víctima, incluidos los de carácter sucesorio. En caso de que no se acredite el feminicidio, se aplicarán las reglas del homicidio.

Al servidor público que retarde o entorpezca maliciosamente o por negligencia la procuración o administración de justicia se le impondrá pena de prisión de tres a ocho años y de quinientos a mil quinientos días multa, además será destituido e inhabilitado de tres a diez años para desempeñar otro empleo, cargo o comisión públicos. (Código Penal Federal, Libro Segundo, Título Decimonoveno, Delitos contra la vida y la integración corporal, Capítulo V-Feminicidio, art. 325)

Desde sus inicios, se intentaba quebrar la aparente igualdad entre el homicidio y el feminicidio partiendo de los motivos de género, es decir, de la misoginia o del odio contra mujeres por el hecho de serlo, y así mismo, establecer diseños de investigación y de persecución del delito de manera específica y diferente, teniendo en cuenta la anhelada perspectiva de género (Núñez, 2018).

También, se pretendía, mediante la tipificación, contar con registros y datos oficiales que permitiera estudiar y visibilizar las dimensiones del fenómeno y que facilitara la asertividad de políticas públicas para su prevención fundamentalmente (Núñez, 2018). La invisibilidad de las mujeres asesinadas por el hecho de ser mujeres conformaba una segregación post mortem por razones de género y esto reforzaba aún más la inexistencia de los cuerpos de las mujeres frente al aparato de justicia penal dominado por hombres, pensado por hombres y edificado por hombres. 
A pesar de los esfuerzos por impregnarle al nuevo tipo penal de feminicidio su naturaleza estructural y sistémica, esta no pudo ser conseguida en solo siete numerales redundantes en hechos de carácter interpersonal, y cuando no queda clarificado qué se entenderá por "razones de género" (Núñez, 2018).

De hecho, el género se encuentra visiblemente reducido a la diferencia sexual mediante una víctima mujer y una persona victimaria a la que no se le asignó ninguna identidad de género.

La impunidad, en cambio, ha sido articulada mediante el último párrafo referente a los servidores públicos que atenten contra la persecución del delito.

La tipificación penal del delito de feminicidio en el Código Penal Federal mexicano favorece más el reconocimiento social, jurídico, penalista y para todos los operadores del derecho acerca del complejo fenómeno de la violencia de género que a su solución misma. Es ficcional pretender que un tipo penal reconocido despliegue efectos preventivos y disuasivos por sí mismo y de manera aislada. Es inoperante analizar un delito en desconexión del entramado judicial, estatal e institucional. No obstante, también resulta simplificante menospreciar la dimensión axiológica del derecho y de las leyes en general, las que consideran a su vez la rama penal. Existe en la tipificación del feminicidio un simbolismo nada despreciable, incluso con sus contradicciones y omisiones como es el caso que nos ocupa.

Así como el feminicidio en su proceso de construcción, elaboración y aplicación subsume una serie de tecnologías sociales y de género, al mismo tiempo funda una nueva.

Si bien la tipificación del feminicidio para el caso mexicano excluye otras identidades de género y otras subjetividades, su sola comprensión permite el reconocimiento de mujeres asesinadas por la particularidad de "ser mujeres".

La ilusión positivista y legalista blinda la formulación de nuevas leyes y soluciones ante el fenómeno multidimensional y múltiple de las violencias basadas en género. 


\section{Travesticidio y transfemicidio en el caso argentino}

Lo ha dicho Diana Maffía (2018), el femicidio es un concepto que no permite abordar e investigar adecuadamente los asesinatos de personas trans y travestis. La razón de esta barrera no es únicamente legal.

El travesticidio y el transfemicidio son también las violencias más extremas y finales de un encadenamiento previo de violencias y desigualdades específicas contra un colectivo de personas no adscriptas al cisexismo, es decir, al sistema binario excluyente, que responde a una estructuración cultural, social, económica y política que expulsa, invisibiliza y desconoce los cuerpos no binarios, no cisgénero. Estos crímenes son la "otra" punta del iceberg.

Las personas trans/travestis portan una desobediencia simbólica en sus propios cuerpos y subjetividades, lo que las colocan en un lugar material "mucho más expuesto a la muerte prematura y violenta" (Maffía, 2018, p. 85): en Argentina, el 90\% de las mujeres trans subsisten por medio del trabajo sexual, la esperanza de vida de las personas que integran estas comunidades no supera los 41 años, y las principales causas de muerte son el llamado "homicidio transfóbico" y el abuso policial (Colque et al., 2020).

El contínuum de violencias comienza con la expulsión del hogar, la exclusión del sistema educativo, del sistema sanitario y del mercado laboral, la iniciación temprana en la prostitución/el trabajo sexual, el riesgo permanente de contagio de enfermedades de transmisión sexual, la criminalización, la estigmatización social, la patologización, la persecución y la violencia policial. Esta trama de violencias constituye el espacio de experiencia de travestis y mujeres trans y se espeja en su menguado horizonte de expectativas. (Maffía, 2018, p. 85)

Asimismo, existen otras particularidades que modelan los delitos de travesticidio/transfemicidio: marcas corporales que denotan una brutalidad excesiva al momento de cometer el crimen y los agresores no suelen tener vínculos familiares con la víctima.

Si nos adentramos en el proceso de investigación, los sesgos se multiplican. Con frecuencia se rotula el expediente como individuos masculinos NN y los pocos casos que llegan a procesarse, quedan impunes. Los esquemas de peritaje forense o médico-legista no reflejan 
la realidad material de los cuerpos no binarios: se emplea una lámina con un dibujo de mujer cis o se emplea el de un hombre cis, o ambas, pero jamás la de un cuerpo con senos y pene (Maffía, 2018).

A pesar de las pujas de los movimientos feministas, de mujeres y LGBTIQ+, en Argentina se aprobó como agravante de la figura del homicidio definiciones que pertenecen a los conceptos de femicidio, travesticidio y transfemicidio. Es decir, en el año 2012 estos conceptos no fueron aprobados como tipos penales específicos e independientes del homicidio, sino como formas agravadas de este, sin embargo, su formulación permite asimilarlos.

Se impondrá reclusión perpetua o prisión perpetua, pudiendo aplicarse lo dispuesto en el artículo 52, al que matare:

$1^{\circ}$ A su ascendiente, descendiente, cónyuge, excónyuge, o a la persona con quien mantiene o ha mantenido una relación de pareja, mediare o no convivencia.

\section{(..)}

$4^{\text {o }}$ Por placer, codicia, odio racial, religioso, de género o a la orientación sexual, identidad de género o su expresión.

\section{(...)}

11. A una mujer cuando el hecho sea perpetrado por un hombre y mediare violencia de género. (Código Penal Argentino, Libro Segundo, Título I Delito contra las personas, Capítulo I Delitos contra la vida, art. 80)"

Los numerales 1 y 11 se relacionan con varios de los elementos tipificantes del femicidio, mientras el 4 se equipara al travesticidio y transfemicidio a partir de la regulación de término como el "odio de género", “odio a la identidad de género", “odio a la expresión de género”, aunque es relevante también que se alegue el placer y la codicia.

Sin duda alguna la redacción del artículo 80 permite una ampliación de los sujetos pasivos en los asesinatos por motivos de género. El género se desmarca de la tradición binaria y biologicista y es asumido de manera plural por la ley penal argentina.

No obstante, el odio no explica toda la madeja de causas que provoca el entramado de desigualdades y violencias que afectan a la co- 
munidad trans y travesti. La redacción de la norma coloca el fenómeno en términos particulares e interpersonales cuando son estructurales y colectivos. Incluso, para cuando se aprobó la incorporación de estas formas agravadas no existía un registro sistematizado de crímenes de este tipo en el país.

Tampoco la impunidad ni el efecto del abuso policial como causal sistemática en la comisión de violencias y asesinatos contra personas trans y travestis encuentran articulación en la formulación legal anteriormente citada.

La pertinencia de estos conceptos no se limita a la regulación positivista del delito, las personas trans y travestis se insertan en una colectividad con desigualdades y violencias particulares que se reproducen diferenciadamente a la de mujeres cisgénero que también debe permear la ley. No se trata únicamente del reconocimiento de un rasgo identitario, sino que es importante señalar las condiciones específicas de marginación y vulnerabilidad de todo un grupo social.

De igual manera las ventajas procesales y simbólicas que despliegan este tipo de reconocimientos penales se repiten como en el caso del femicidio: diseños específicos de investigación y de persecución del delito, protocolos especializados para estos tipos penales, comprensión de la naturaleza estructural, articulación de políticas públicas diferenciadoras y a su vez plurales y no binarias, corresponsabilidad estatal en todo el encadenamiento de violencias, entre otras.

\section{La violencia de género del caso cubano}

En Cuba no se reconoce el feminicidio, tampoco el travesticidio ni el transfeminicidio. Tampoco se cuenta con una ley contra la violencia de género ni intrafamiliar. Las violencias basadas en género y sexualidad con cierta especialización no se encuentran reguladas, apenas limitadas al parentesco y los vínculos afectivos.

A pesar de que el país se encuentra a las puertas de un nuevo Código Penal y su ley adjetiva, la postura oficial parece estar inclinada a seguir desconociendo estas tipificaciones. Los argumentos se sostienen en que, aunque no existan estos tipos penales, con las figuras actuales, todos los asesinatos $\mathrm{u}$ homicidios pueden ser atendidos y procesados conforme a la ley (Canal Cubadebate, 2021; Figueredo et al, 2021). 
Si bien Cuba no presenta un sistema penal que estructuralmente favorezca la impunidad, lo cierto es que limitar la respuesta penal frente a estos crímenes a ser atendidos o no, sin asimilar las desigualdades estructurales y el contínuum de violencias que les preceden es una forma más de reificar la ilusión de la igualdad entre los sexos, manteniéndola bajo el manto de la dominación masculina en un (cis)tema tradicionalmente binario y biologicista.

De hecho, todavía no existen registros oficiales ni públicos que sistematicen este tipo de crímenes.

En el informe voluntario que presentara Cuba ante la CEPAL en el 2019, se dio a conocer la primera tasa de femicidios en el país registrada en el 2016 (0,99 por cada 100 mil mujeres de 15 años y más), aunque el dato se presentaba como un subregistro debido a que solo se tomaba en cuenta la preexistencia de un vínculo sentimental entre víctima y victimario para considerarlo como feminicidio (Grupo Nacional para la Implementación de la Agenda 2030, 2019). Más recientemente, el informe voluntario ante la misma organización, pero del año 2021 señaló otro dato: la tasa de mortalidad femenina por agresiones es de 1,9 por cada 100 mil mujeres (Grupo Nacional para la Implementación de la Agenda 2030, 2021). Sin embargo, estos datos no están desagregados por identidad de género, orientación sexual, edad, territorios ni color de la piel.

El cambio semántico de tasa de femicidios a tasa de mortalidad femenina por agresiones manifiesta la ausencia de un debido protocolo de clasificación y registro, o bien, una intencionalidad política de exclusión de términos que aún no son asimilados por el entramado institucional ni por las leyes.

En Cuba los feminicidios, los travesticidios y los transfeminicidios existen sin lugar a duda, sin embargo, la resistencia estatal a su reconocimiento y regulación es altamente notoria (Canal Cubadebate, 2021; Figueredo et al, 2021).

Uno de los puntos nodales en la discusión institucional estriba en la necesidad de diferenciar femicidios de feminicidios. Se plantea que, cuanto más, en Cuba ocurren femicidios ya que los asesinatos de mujeres por motivos de género no se consideran crímenes de Estado. 
En efecto, ya se ha mencionado que, estructuralmente, la impunidad no es un elemento que caracterice al sistema penal cubano, tampoco el Estado se convierte en cómplice de ese resultado máximo de la violencia de género como lo son este tipo de asesinatos. No obstante, el feminicidio no es equivalente a colocar automáticamente un Estado en un estatus criminal o cómplice. Los efectos del reconocimiento y tratamiento en la ley de estos tipos penales trascienden la significancia de un epíteto o la calificación de un sistema a partir de una teorización en movilidad y constante ampliación y resignificación como lo es el feminicidio.

No obstante, más allá de las consecuencias calificativas que pueda traer consigo el uso de un concepto u otro, los aportes más relevantes de los estudios académicos feministas en relación con el fenómeno femicidio/feminicidio han sido dos:

- El carácter estructural y sistemático que evidenció Russell de ese contínuum de violencias basadas en el género que terminan en su extremo con la muerte, entendiendo que no es un asunto privado sino público.

- La responsabilidad de los Estados que visibilizó Lagarde en la prevención y atención de todas las relaciones que hacen posible ese contínuum de violencias que pueden terminar en el asesinato por razones de género de manera tal de evitar la impunidad en cualquier escala, entendiendo que son problemas que no solo trascienden de lo privado a lo público, sino que además son problemas políticos que necesitan la intervención estatal para transformar todos los parámetros desde la base.

La lupa colocada por Lagarde sobre la impunidad y la complicidad vino a descarnar lo que se entiende por corresponsabilidad estatal para la prevención, interrupción y disminución de las violencias basadas en género y sexualidad, pero también de las desigualdades estructurales que las provocan.

Según la Encuesta Nacional de Igualdad de Género de 2016, el $26,7 \%$ de las mujeres cubanas entre 15 y 74 años fueron víctimas de alguna manifestación de violencia en su relación de pareja durante los 12 meses previos al estudio, y un 22,6\% lo fue, además, en "algún otro momento de su vida". Pero, como consecuencia del débil tejido insti- 
tucional y tratamiento legal de protección eficiente contra la violencia de género específicamente, las mujeres no recurren a las instituciones. Solo el 3,7\% de las mujeres cubanas que declaró haber sufrido violencia en el marco de sus relaciones de pareja solicitó algún tipo de ayuda institucional, a pesar de que ante una agresión, el $57,4 \%$ se divorciaría de su pareja y el $8,1 \%$ optaría por irse de la casa (Oficina Nacional de Estadística e Información, 2016).

En contraste, datos globales revelan que el $18 \%$ de las mujeres en el mundo fueron víctimas de violencia en su relación de pareja en los últimos doce meses y que alrededor del $10 \%$ acude a denunciar a la policía (Organización de las Nacionales Unidas [ONU Mujeres], 2019).

Es decir, abandonar la pareja, la casa y salir del círculo de la violencia se encuentran entre las respuestas a una agresión para las mujeres cubanas, pero las instituciones parecen no ser confiables o no proporcionar el tratamiento adecuado (ni social, ni legal) ante este tipo de fenómenos. De hecho, otra ausencia notoria en las políticas públicas cubanas para el enfrentamiento de la violencia basada en género y sexualidad son los refugios para víctimas como medida de emergencia.

Las desigualdades históricas y estructurales también se reproducen en el país caribeño. Las cubanas dedican más tiempo que los hombres a las tareas domésticas en el hogar (14 horas más como promedio en una semana). Del total de personas ocupadas formalmente en la economía, el 39\% son mujeres (el 29,1\% del sector privado y el 35,5\% en el trabajo por cuenta propia o autoempleo). Aunque la Constitución cubana estipula que las mujeres reciban igual salario por igual trabajo que los hombres, ellas siguen sobrerrepresentando las actividades con menor salario medio. Por su parte, se ha experimentado un aumento del número de mujeres solas a cargo de los hogares frente a una crisis generalizada de los cuidados (Grupo Nacional para la Implementación de la Agenda 2030, 2021).

Por su parte, para el año 2017 se calculaba que la población trans en Cuba era de entre las 3 mil y las 3 mil 500 personas; el dato no es preciso debido, precisamente, a la invisibilidad de estas colectividades en los censos oficiales. La mayoría son mujeres trans de piel blanca, pero 
con una sobrerrepresentación de mujeres trans negras de acuerdo con cada grupo marcado por la raza (Iglesias et al., 2017).

De ese universo, el 92,6\% alcanza como máximo nivel de instrucción la enseñanza media y solo el 2,8\% logra graduarse en la universidad. Respecto del empleo, el 39,9\% de las personas trans se encuentra vinculada al estudio o al trabajo, mientras que $43 \%$ está buscando trabajo (Iglesias et al., 2017).

En términos de violencia de género, las cifras son alarmantes: el $47,8 \%$ recibió agresiones físicas por parte de sus parejas durante el año anterior al estudio; el 57,8\% fue víctima de violencia sexual; y el 96,5\% de violencia psicológica (Iglesias et al., 2017).

Por su parte, el $87 \%$ de la población cubana ha referido rechazo hacia la comunidad trans, manifestando que no se les debe aceptar en los centros de trabajo con vestimenta que no sea la correspondiente a su sexo biológico y que deben ser llamadas de acuerdo con el nombre que indica el documento legal de identificación. Más de la mitad de las personas encuestadas por el referido estudio admitieron que no vivirían bajo el mismo techo que una persona trans (Iglesias et al., 2017).

Si ante este escenario agregamos los obstáculos que se presentan para acceder a la justicia penal como mujeres o personas trans/travestis, la vulnerabilidad de la vida y de la integridad física de estos sujetos se multiplica. Incluso, las personas trans que acuden a denunciar a una estación de policía terminan criminalizadas (García, 2020). Frente a esto, el Estado cubano es responsable.

Volviendo a Teresa de Lauretis (1989), el género es producto de varias tecnologías sociales, entre ellas el discurso institucional, incluidas las teorías y nomenclaturas legales. Desconocer, expulsar e invisibilizar también configura una producción de género: aquella que es negada y pugna por su reconocimiento.

Todas las barreras impuestas por un Estado que conlleva a la desaparición de una serie de subjetividades representan un lenguaje claro de su dominación masculina, de su blindaje patriarcal y colonial. En contraste, los movimientos de mujeres y personas diversas continúan infiltrando en el escudo institucional sus demandas y disputas por el 
reconocimiento de otras subjetividades, lo que hace que esas fisuras se conviertan en un destino inevitable.

\section{Cuando el género no alcanza}

La feminista venezolana Esther G. Pineda (2019) se ha referido al afrofemicidio, como una tipología especial de asesinato no solamente dado por motivos de género, sino también por la condición étnicoracial. Esta imbricación históricamente desplazada alcanza mayor visibilización a partir de las epistemologías provenientes del feminismo negro y el feminismo de color.

Las mujeres negras y afrodescendientes en todo el continente americano han sido atravesadas por los largos siglos de esclavización, con violencias específicas y sistemáticas como la violación, el trato deshumanizante y cruel, y la cosificación/animalización de sus cuerpos; desde la obscena representación de sus subjetividades hasta las políticas de genocidio basadas en el odio racial.

Por tanto, las desigualdades que impactan en especial a las mujeres afrodescendientes son múltiples y interseccionales, edificadas sobre los pilares de un sistema profundamente racista, patriarcal, misógino y colonial.

De ahí que la autora defina el afrofemicidio como "el asesinato de mujeres negras y afrodescendientes a manos de hombres (blancos y no blancos), el cual puede tener como motivación la misoginia y el sexismo, pero también motivaciones racistas" (Pineda, 2019, p. 5).

Las violaciones masivas seguidas del asesinato a mujeres afrodescendientes en los Estados Unidos también tuvieron lugar durante el movimiento por los derechos civiles y políticos de las comunidades afro de ese país, como parte de una estrategia de guerra en contra de este, principalmente articuladas por miembros del Ku Klux Klan (Pineda, 2019).

Actualmente existen pocos datos que desagregan la condición racial de las víctimas de feminicidios, travesticidios y transfeminicidios, no obstante, el racismo estructural incide categóricamente en la manera en que representamos al género y en la forma en que se infunden $\mathrm{y}$ atienden las violencias basadas en género y sexualidad. 
Si bien el análisis y planteamiento de Pineda visibiliza un fenómeno poco abordado en los estudios sobre violencia de género, se limita a la negritud o afrodescendencia de las mujeres.

En La guerra contra las mujeres la antropóloga Rita Segato (2016) relata la situación de vulnerabilidad, desapariciones y asesinatos sistemáticos que impactaban a las mujeres de Ciudad Juárez en México. Pero no son solo mujeres, son mujeres que viven en un estado fronterizo, empobrecidas, racializadas, vinculadas al trabajo precario de las maquiladoras en el contexto del ascenso del capitalismo neoliberal y trasnacional.

El secuestro, la tortura, la violación tumultuaria, el estrangulamiento, la mutilación, la muerte segura y la impunidad conformaban el panorama de la violencia feminicida, muy diferente al feminicidio doméstico. Esto, a su vez, produce significaciones y representaciones que refuerzan un disciplinamiento social, una obediencia grupal y una subordinación marcada por el género, pero también por la clase, la raza, el origen étnico y el territorio. Es la articulación enunciativa y reproductiva de un sistema de poder (capitalista, racista y colonial) que se legitima en forma de guerra silenciosa sobre el cuerpo de esas mujeres.

Por su parte, entre los años 1996 y 2000 el gobierno de Alberto Fujimori en Perú ordenó una política de planificación familiar que abarcó la esterilización forzada de unas 300 mil personas. De ellas, $250 \mathrm{mil}$ fueron mujeres, pero no cualquier tipo de mujer: estas tenían en común ser indígenas o ser de procedencia rural, empobrecidas o de bajos recursos económicos. Para ello, se improvisaron salas de cirugía precarias, donde se intervenía masivamente a las mujeres, llegando a operar hasta 60 por día. Hasta el 2017 se habían presentado unas dos mil denuncias ante la Fiscalía de la Nación (Molina, 2017).

Sin embargo, estos hechos se conectan con las agresiones provenientes del Estado y de grupos terroristas en esos territorios. La población indígena ha sido históricamente desplazada y agredida. Durante el conflicto armado la violencia se concentró en los departamentos más empobrecidos del país y la mayoría de las víctimas fue de campesinas de bajos recursos. Una vez más se asoma la violencia de género como estrategia de guerra mediante el cuerpo de las mujeres. 
Por otra parte, El Salvador, Honduras y Guatemala conforman lo que se conoce como el Triángulo Norte Centroamericano (TNCA), uno de los territorios más peligrosos del mundo. Globalmente, estos tres países se encuentran entre los 23 con mayores tasas de homicidio, además de niveles de violencia solo comparables con países que presentan o han presentado conflictos armados tradicionales, por ejemplo, el segundo país más violento del mundo lo ocupa Honduras (solo después de Siria), El Salvador es el sexto y Guatemala el onceno (Prado, 2018). Sin embargo, la violencia no es uniforme; está distribuida de manera desigual, concentrándose en zonas rurales, periféricas o fronterizas, además de afectar principalmente a las clases sociales más bajas (Reséndiz, 2017).

La explicación se completa cuando imbricamos este fenómeno con el efecto de las posguerras, las pandillas y el crimen organizado como una "nueva" forma de guerra no tradicional.

Asimismo, no es casual que las tasas de feminicidio de los países que conforman el TNCA sean a su vez las más altas de la región (El Salvador y Honduras en los dos primeros lugares, y Guatemala en el cuarto) (Comisión Económica para América Latina y el Caribe [CEPAL], 2019) No obstante, estas cifras deben ser leídas e interpretadas bajo el contexto descrito anteriormente, es decir, condicionadas por la delincuencia organizada y no por la preeminencia del feminicidio íntimo.

En efecto, si encaramos la situación de las mujeres negras y afrodescendientes en Colombia, específicamente en la zona del Pacífico, el distrito de Buenaventura da cuenta de cómo el asesinato sistemático contra las mujeres negras también se des-sitúan del concepto de feminicidio íntimo o causado en el marco de una relación sentimental. Más bien se considera una estrategia de desterritorialización de la población negra para la ejecución de megaproyectos que responden a los intereses del capitalismo global (Lozano, 2016).

No hay que olvidar que la ciudad de portuaria de Buenaventura la habita un $90 \%$ de personas negras o afrodescendiente, un $3 \%$ de personas indígenas y un $7 \%$ de población mestiza; y que los planes de creciente desarrollo vinieron acompañados de un despliegue de fuerzas paramilitares que protegían los intereses de los empresarios y del ca- 
pital, y que se fueron incrementando hacia finales de los $1990 \mathrm{y}$ principios de 2000. Así, entre el 2000 y 2001 tuvo lugar la primera masacre donde se asesinó a más de mil personas (Lozano, 2016).

Las formas más sistemáticas de violencia contra las mujeres afrocolombianas de esta localidad se basan en la trata interna de mujeres entre los grupos armados, el entrenamiento de niñas como informantes que, cuando son atrapadas terminan con sus vidas, el transporte de armas, los asesinatos de lideresas, el reclutamiento sexual de niñas y jóvenes, además de torturas y empalamientos antes de los asesinatos como evidentes mensajes disciplinatorios hacia la comunidad (Lozano, 2016).

En consecuencia de todo lo descrito, Segato (2016) nos habla de femigenocidio: cuando los asesinatos contra mujeres no se producen en el marco de la relación íntima ni por personas conocidas, sino que el carácter masivo responde a una guerra contra el Estado y la sociedad, bajo los intereses de los grandes capitales privados por el sostenimiento de los sistemas de poder capitalista, colonialista, racista y misógino, y que ocurren mediante el cuerpo de las mujeres y no esencialmente contra ellas.

Este fenómeno enuncia mensajes, representaciones, narraciones, poderíos y disciplinamientos a toda la sociedad en clave de género. A su vez ordena una serie de relaciones sociales de carácter colectivo intrínsecamente vinculadas a los territorios, al origen étnico o racial, a la clase e incluso al estatus de movilidad, es decir, considerando los grandes desplazamientos migratorios.

Es otra tecnología social con carácter de guerra, de Estado y delincuencia organizada en nuestros territorios amerindios, negros, fronterizos, rurales y empobrecidos.

En entrevistas la propia Segato (2019) se ha pronunciado a favor del reconocimiento del femigenocidio por parte de la Convención Interamericana de Derechos Humanos como un crimen de lesa humanidad. Para muchas académicas que se pronuncian en contra, estaríamos en presencia de categorías jurídicas y penales de tipo simbólico, y también de eso se trata. Es importante conceptualizar y legalizar aquel fenómeno captado que, por sus magnitudes, precisa la concurrencia de articulaciones ya de tipo regional que la nombren y representen en toda la complejidad y densidad de sus aristas. 
Nuevas tipificaciones y un refinamiento de las definiciones se hacen necesarios para que sea posible comprender la especificidad de un número restringido de las muertes de Juárez; es necesario también formular nuevas categorías jurídicas. Especialmente, es necesario decir lo que parece obvio: que ningún crimen realizado por marginales comunes se prolonga por tanto tiempo en total impunidad, y que ninguna policía seria habla con tamaña liviandad de lo que, en general, es producto de una larga investigación: el móvil, el motivo, la razón de un crimen. Esas verdades elementales causaron estremecimiento en Ciudad Juárez y resultaron impronunciables. (Segato, 2016, p. 37)

\section{Consideraciones finales}

Las leyes en general y las leyes penales en específico ciertamente no serán el milagro que inmediatamente otorgarán igualdades efectivas, no obstante, son instrumentos sociales y políticos que impactan la vida de todas las personas y las formas de relaciones entre ellas, con las instituciones y con el Estado. Ese impacto puede ser más o menos desfavorable para algunas, pero además pueden significar la inexistencia para aquellas que ni siquiera son consideradas personas.

La animalidad con la que históricamente se ha moldeado a las personas afrodescendientes, la cosificación del resto de las personas racializadas y empobrecidas, y la monstruosidad que se le asigna a las personas trans/travestis incluyen barreras agregadas a la subordinación, dueñidad y disciplinamiento reservados a las mujeres.

De ahí que el género no se pueda describir sin el resto de los marcadores sociales como tecnologías que nos configuran la vida y la posición que ocupamos en el amplio entramado de desigualdades y violencias. Las leyes penales están incluidas, nos subsumen, nos desplazan o nos expulsan.

Legislar, ejercer y proceder en materia penal con perspectiva de género e interseccional implica un reconocimiento no solo de las subjetividades, sino también de la manera en que operan los mecanismos de opresión y desigualdad en nuestros territorios y, en específico, las violencias basadas en género.

La tipificación del feminicidio y las figuras afines interpelan más allá de caracterizar un hecho delictivo, sino que tienen la misión de 
nombrar un fenómeno criminal transversal y estructural que se encuentra alimentado y alimentando un sistema capitalista de descarte de cuerpos cosificados en los que el género, la raza, el territorio, entre otros ejes de opresión figuran como los más desechables. Estos tipos penales constituyen la punta del iceberg: desmadejar las profundidades de esas violencias en sus causas y consecuencias es también asimilable por el derecho penal en general. La ley penal como tecnología de género puede considerarse una llave que abra el acceso a la justicia de millones de mujeres y personas diversas que esperan por su reconocimiento siempre y cuando atienda a un enfoque interseccional, integrador y estructural.

Estos análisis no los considero conclusiones ni sentencias firmes ante un fenómeno tan complejo; más bien pretenden ser una especie de intersticios mediante los cuales podamos dinamitar las estructuras rígidas de una ley que permite $\mathrm{u}$ omite nuestras muertes, detonar el sistema que se articula por sobre nuestros cuerpos y nuestros cadáveres.

\section{Referencias}

Bonder, G. (1998). Género y subjetividad: avatares de una relación no evidente. En S. Montesino y A. Obach (Comp.), Género y epistemología: mujeres y disciplinas (pp. 29-55). Programa Interdisciplinario de Estudios de Género. LOM Ediciones.

Canal Cubadebate. (16 de junio de 2021). Esta tarde, Cubadebate en Mesa Redonda ¿Cómo se enfrenta en Cuba la violencia de género? [Archivo de video]. YouTube. https://www.youtube. com/watch?v=GP90MGYR-iM

Comisión Económica para América Latina y el Caribe, CEPAL (2019). La medición del feminicidio o femicidio: desafíos y ruta de fortalecimiento en América Latina y el Caribe. Observatorio de Igualdad de Género de América Latina y el Caribe - CEPAL. https://oig.cepal.org/sites/default/files/femicidio_web.pdf

Colque, A., Pavón, L., y González, J. (2020). Población travestitransgénero en Argentina: Estado de situación frente a la pandemia de COVID-19. (Informe para el Programa de Naciones Unidas para el Desarrollo, PNUD, sobre el COVID-19 y la protección social de los grupos pobres y vulnerables). Tulane University: CEQ Institute Commitment 
to Equity. https://www.latinamerica.undp.org/content/ rblac/es/home/blog/2020/poblacion-travesti-transgeneroen-argentina--estado-de-situacion.html

De Lauretis, T. (1989). Technologies of Gender. Essays on Theory, Film and Fiction. Macmillan

Figueredo, O., Sifonte, Y., Carmona, E., y Terrero, A. (20 de mayo de 2021). Mujeres tras las sombras: desafíos del femicidio en Cuba (II). Cubadebate. http://www.cubadebate.cu/ especiales/2021/05/20/mujeres-tras-las-sombras-desafiosdel-femicidio-en-cuba-ii/

García, K. (28 de junio de 2020). Las identidades trans en conflicto con la ley penal: una mirada desde el sistema de justicia cubano. Diagonalciep. https://diagonalciep.org/las-identidadestrans-en-conflicto-con-la-ley-penal-una-mirada-desde-elsistema-de-justicia-cubano/

Grupo Nacional para la Implementación de la Agenda 2030. (2019). Cuba. Informe nacional sobre la implementación de la Agenda 2030. Centro de Pensamiento Estratégico Internacional, Cepei. https://cepei.org/wp-content/ uploads/2020/01/informe_nacional_voluntario_de_cuba_ sobre_implementacion_de_la_agenda_2030.pdf

Grupo Nacional para la Implementación de la Agenda 2030. (2021). Cuba. Informe nacional voluntario Cuba 2021 sobre la Agenda 2030. Ministerio de Economía y Planificación de Cuba, MEP. https://www.mep.gob.cu/es/noticia/informenacional-voluntario-cuba-2021-sobre-la-agenda-2030

Iglesias, M., González, H., y Mena, M. (2017). Caracterización sociocultural y demográfica de las personas trans en Cuba. Actitudes discriminatorias hacia ellas. Culturales, 1(1), 189216. http://www.scielo.org.mx/scielo.php?script=sci_arttext\& pid=S1870-11912017000100189

Lagarde, M. (2005). ¿A qué llamamos feminicidio? (Informe Sustantivo $\mathrm{n}^{\circ}$ 1, Comisión Especial para Conocer y dar seguimiento a las Investigaciones Relacionadas con los Feminicidios en la República Mexicana y a la Procuración de Justicia Vinculada en la LIX Legislatura Cámara de Diputados H. Congreso de la Unión). Cátedra Unesco. https://catedraunescodh.unam. $\mathrm{mx} /$ catedra/mujeres/menu_superior/Feminicidio/2_Info_ nac/12.pdf 
Lozano, B. (2016). Violencias contra las mujeres negras: Neo conquista y neo colonización de territorios y cuerpos en la región del Pacífico colombiano. La manzana de la discordia, 11(1), 7-17. https://doi.org/10.25100/lamanzanadeladiscordia.v1li1.1630

Maffía, D. (2018). Travesticidio/Transfemicidio como crimen de género. Jueces para la democracia, (93), 79-92.

Molina, A. (2017). Esterilizaciones (forzadas) en Perú: Poder y configuraciones narrativas. AIBR, Revista de Antropología Iberoamericana, 12(1), 31-52.

Molyneux, M. (2017). Entre las luchas feministas y las respuestas conservadoras/Entrevistada por Mariano Schuster. Nueva Sociedad. https://nuso.org/articulo/luchas-feministasmolyneux/

Núñez, L. (2018). El género en la ley penal: crítica feminista de la ilusión punitiva. Universidad Nacional Autónoma de México, UNAM.

Oficina Nacional de Estadística e Información. (2016). Encuesta Nacional sobre Igualdad de Género ENIG-2016 Informe de Resultados diciembre 2020. ONEI. http://www.onei.gob.cu/ node/14271

Organización de las Nacionales Unidas, ONU-Mujeres. (2019). Hechos y cifras: Poner fin a la violencia contra las mujeres. Unwomen. https://www.unwomen.org/es/what-we-do/ ending-violence-against-women/facts-and-figures

Palomar, C. (2016). Veinte años de pensar el género. Debate Feminista, (52), 35-49. https://debatefeminista.cieg.unam.mx/df_ojs/ index.php/debate_feminista/article/download/2081/1873/

Pineda, E. (2019). El feminismo negro y el afrofemicidio. Africanía, (3), 4-7. https://diariofemenino.com.ar/df/el-feminismonegro-y-el-afrofemicidio/

Prado, R. (2018). El entramado de violencias en el Triángulo Norte Centroamericano y las maras. Sociológica, 33(93), 213-246. http://www.scielo.org.mx/scielo.php?script=sci_arttext\&pi $\mathrm{d}=\mathrm{S} 0187-01732018000100213$

Radford, J. y Russell, D. (1992). Femicide: The politics of woman killing. Twayne Publishers.

Reséndiz, N. (2017). Mujeres, pandillas y violencia en Guatemala. Cuadernos Inter.c.a.mbio sobre Centroamérica y el Caribe, 
14(1), 50-75. https://dialnet.unirioja.es/descarga/
articulo/5922109.pdf

Segato, R. (2016). La guerra contra las mujeres. Traficante de sueños. https://www.traficantes.net/sites/default/files/pdfs/ map45_segato_web.pdf

Segato, R. (2019). Guerra contra la sociedad se realiza en el cuerpo de las mujeres: Laura Segato/Entrevistada por la Ibero, Universidad Iberoamericana Ciudad de México. Ibero. https://ibero.mx/prensa/guerra-contra-la-sociedad-serealiza-en-el-cuerpo-de-las-mujeres-laura-segato

Viturro, P. (2006). Constancias. Revista sobre la enseñanza del Derecho en Buenos Aires, 3(6), 295-300. http://www.derecho.uba.ar/ publicaciones/rev_academia/revistas/06/constancias.pdf 